\title{
Ventricular apparent diffusion coefficient measurements in patients with neoplastic leptomeningeal disease
}

James M. Debnam", Ryan B. Said ${ }^{1}$, Heng-Hsiao Liu', Jia Sun², Jihong Wang ${ }^{3}$, Wei Wei², Dima Suki ${ }^{4}$, Rory R. Mayer ${ }^{5}$, T. Linda Chi ${ }^{1}$, Leena Ketonen ${ }^{1}$, Nandita Guha-Thakurta ${ }^{1}$ and Jeffrey S. Weinberg ${ }^{4}$

\begin{abstract}
Background: To test the hypothesis that intraventricular ADC values can be used to determine the presence of neoplastic leptomeningeal disease (LMD).

Materials and methods: ADC values were measured at multiple sites in the ventricular system in 32 patients with cytologically-proven LMD and 40 control subjects. Multiple linear regression analysis was used to determine the mean difference of ADCs between the LMD and control groups after adjusting for ventricle size and tumor type. Receiver operating characteristics (ROC) analysis was performed and optimal ADC value cut-off point for predicting the presence of $L M D$. ADC was compared to $T 1$ enhancement and FLAIR signal hyperintensity for determining the presence of LMD.

Results: After adjusting for ventricular volume and tumor type, the mid body of lateral ventricles showed no significant difference in ventricular volume and a significant difference in ADC values between the control and LMD groups $(p>0.05)$. In the mid-body of the right lateral ventricle the AUC was 0.69 ( $95 \% \mathrm{Cl} 0.57-0.81)$ with an optimal ADC cut off point of $3.22 \times 10^{-9} \mathrm{~m}^{2} / \mathrm{s}$ (sensitivity, specificity; $0.72,0.68$ ). In the mid-body of left lateral ventricle the AUC was $0.7(95 \% \mathrm{Cl} 0.58-0.82)$ with an optimal cut-off point of $3.23 \times 10^{-9} \mathrm{~m}^{2} / \mathrm{s}(0.81,0.62)$. Using an average value of HU measurements in the lateral ventricles the AUC was $0.73(95 \% \mathrm{Cl} 0.61-0.84)$ with an optimal cut off point was $3.11 \times 10^{-9} \mathrm{~m}^{2} / \mathrm{s}(0.78,0.65)$. Compared to the T1 post-contrast series, ADC was predictive of the presence of LMD in the mid-body of the left lateral ventricle $(p=0.036)$.

Conclusion: Complex interactions affect ADC measurements in patients with $L M D$. ADC values in the lateral ventricles may provide non-invasive clues to the presence of LMD.
\end{abstract}

Keywords: Apparent diffusion coefficient, Ventricles, Cerebrospinal fluid, Magnetic resonance imaging

\section{Introduction}

Leptomeningeal disease (LMD) is the dissemination of cancer cells throughout the leptomeningeal space and portends a dismal prognosis with increased mortality rates [1-7]. Rarely seen only a few decades ago, the

\footnotetext{
* Correspondence: Matthew.Debnam@mdanderson.org

${ }^{1}$ Department of Neuroradiology, The University of Texas MD Anderson Cancer Center, 1400 Pressler Blvd., Unit 1482, Houston, TX 77030, USA Full list of author information is available at the end of the article
}

incidence of LMD has been increasing since then, now occurring in $3-8 \%$ of patients with cancer, [1-3] likely related to improved survival and advances in imaging techniques.

The National Comprehensive Cancer Network requires one of the following three criteria to diagnose LMD: (1) tumorous cells in the CSF on cytological evaluation, (2) clinical and CSF laboratory findings in keeping with LMD (elevated protein and white blood

C C The Author(s). 2020 Open Access This article is licensed under a Creative Commons Attribution 4.0 International License, which permits use, sharing, adaptation, distribution and reproduction in any medium or format, as long as you give appropriate credit to the original author(s) and the source, provide a link to the Creative Commons licence, and indicate if changes were made. The images or other third party material in this article are included in the article's Creative Commons licence, unless indicated otherwise in a credit line to the material. If material is not included in the article's Creative Commons licence and your intended use is not permitted by statutory regulation or exceeds the permitted use, you will need to obtain permission directly from the copyright holder. To view a copy of this licence, visit http://creativecommons.org/licenses/by/4.0/ The Creative Commons Public Domain Dedication waiver (http://creativecommons.org/publicdomain/zero/1.0/) applies to the data made available in this article, unless otherwise stated in a credit line to the data. 
cell counts and low glucose level) in patients with a cancer, or (3) demonstration of LMD on radiological studies regardless of the clinical examination [8]. Although the diagnosis of LMD via cerebrospinal fluid (CSF) cytology is the gold standard, it is invasive and is only $80-95 \%$ sensitive [4]. MRI is also a valuable adjunct and alternative to repeated large-volume CSF analysis $[5,6]$. Gadolinium-enhanced T1-weighted and post-contrast FLAIR MRI remain the most sensitive imaging techniques for diagnosing $\operatorname{LMD}[3,7,9]$ as tumor cells adhere to the leptomeninges [10-12]. However, in the literature the sensitivity of MRI in this setting ranges between 53 and 79\% [13-18].

Diffusion-weighted imaging is a method with wide applications in stroke and tumor imaging [19-21]. In this procedure, the magnitude of fluid movement within a voxel is measured according to the apparent diffusion coefficient (ADC). A low ADC value indicates decreased molecular movement in the tissue sample, whereas a high ADC value indicates freer diffusion.

Radioisotope CSF flow studies have demonstrated compartmentalization of CSF in patients with LMD [2226]. Thus, we hypothesized that compartmentalization of CSF will restrict movement of CSF and lead to decreased $\mathrm{ADC}$ values. Potentially, measuring ADC values could be a non-invasive technique to predict the presence of LMD in patients with cancer. Therefore, the purpose of this study was to measure and compare the ADC values in the ventricular system in patients with active cancer and LMD compared to a control group of patients with a prior history of cancer who are clinically NED (no evidence of disease).

\section{Materials and methods Subjects}

The study was approved by our Institutional Review Board who waived the requirement for informed consent. Data acquisition was performed in compliance with all applicable Health Insurance Portability and Accountability Act regulations. Clinical data and imaging studies were reviewed to identify patients with histological diagnoses of breast cancer or lymphoma via lumbar puncture who underwent conventional MRI of the brain with ADC maps. Patient were included in the study group if they had an MRI examination of the brain with T1 post-contrast and FLAIR sequences, and cytological evidence of LMD. Patients in the control group had a similar MR examination of the brain, available cytological evaluation of CSF has to be negative for disease involvement, and the patients were clinically asymptomatic classifying them as NED.

\section{Imaging protocol}

MRI was performed following our institutional protocol which may have slightly varied during the study timeframe. MRI studies of the brain were performed on $1.5 \mathrm{~T}$ scanners (GE Healthcare, Milwaukee, Wisconsin). Typical examinations included contrast-enhanced axial T1-weighted spin-echo (TR/TE, 850/14-22) and FLAIR (TR/TE, 10000/147) imaging. Axial DTI (TR/TE, 11400/ $8-15)$ was performed with a $B$ value of $0 \& 1200(27-32$ directions) with a slice thickness of $3.5 \mathrm{~mm}$ and an acquisition time of approximately $5 \mathrm{~min}$. Diffusion tensor images were analyzed using the FuncTool software program (version 4.5.3) on an AW workstation (version 4.4; both from GE Healthcare). ADC was defined using the formula $A D C=\frac{\lambda_{1}+\lambda_{2}+\lambda_{3}}{3}$, in which $\lambda_{1}, \lambda_{2}$, and $\lambda_{3}$ are the 3 eigenvalues calculated using diffusion tensor images.

We hypothesized that multiple complex interactions may affect $\mathrm{HU}$ values in the ventricular system including but not limited to various diameters of different components of the ventricular system, pressure differences, CSF flow rate and eddy formation. Therefore, to determine if there is a single or multiple sites where ventricular ADC values are different between the study and control groups, ROIs were independently drawn manually on ADC maps in the frontal horns, mid-body, and atria of the lateral ventricles bilaterally, and in the 3rd and 4th ventricles for both the control and study groups by a neuroradiologist (JMD) and a radiology resident (RBS) who were not blinded as the presence or absence of active disease (Figs. 1 and 2). All ADC values were automatically calculated and expressed in $\mathrm{m}^{2} / \mathrm{s}$. To minimize partial volume effects, axial slices were localized for analysis by identifying regions for which the slices were present immediately superior and inferior to site where the ROI was placed. Care was taken to ensure that the ROIs in all scans was between 25 and $30 \mathrm{~mm}^{2}$ and an effort was made to exclude the choroid plexus from the measured sites.

To determine if ventricular volume affects the ADC values, the volume of the lateral, 3rd and 4th ventricles were measured by consensus using imaging biomarker explorer (IBEX) software that was developed "in-house" and enabled us to measure the ventricular volumes [27]. For comparison in both the LMD and control groups, the presence of leptomeningeal enhancement and FLAIR signal hyperintensity on conventional MR imaging were recorded as being present or absent.

\section{Statistical analysis}

Intraclass correlation coefficient (ICC) with $95 \%$ confidence intervals $(\mathrm{CI})$ was used to evaluate the interreader agreement of the ADC measurements. The ICCs for all observations for each subsite were calculated using the two-way mixed effect model (ICC [C,1]).

ADC measurements from the two reviewers were averaged for data analysis. Descriptive statistics for 


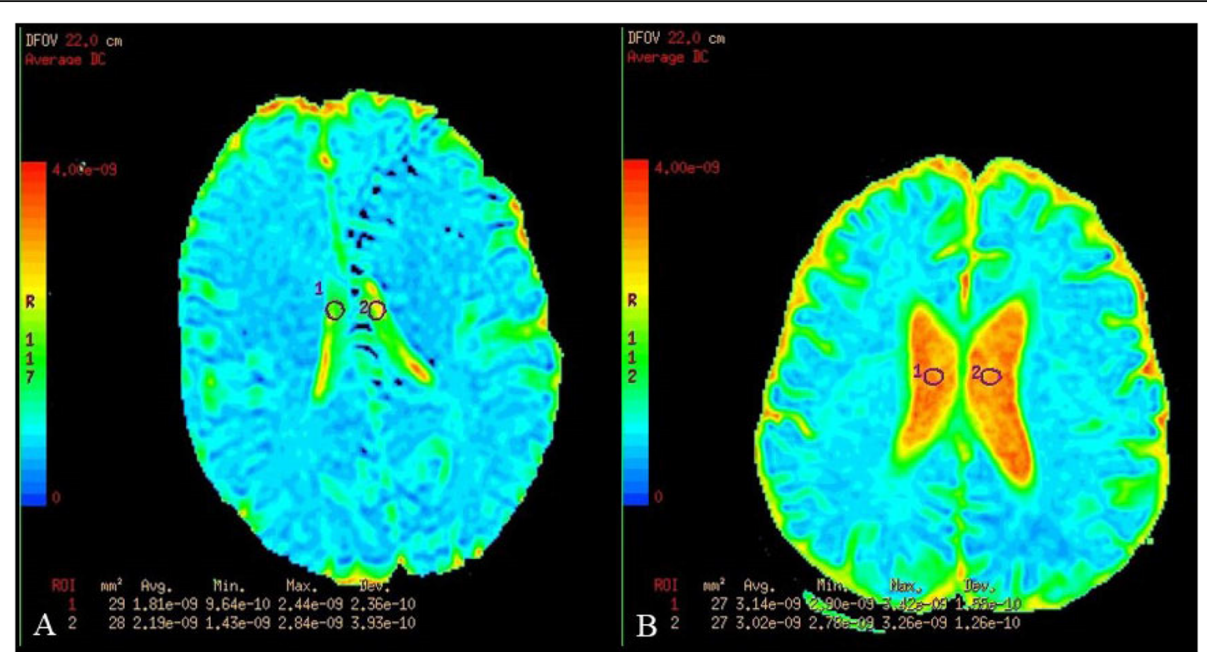

Fig. $1 \mathrm{ROI}$ placement in the mid body of the lateral ventricles of the control groups. a, Breast cancer control. ADC values were $1.81 \times 10^{-9} \mathrm{~mm} / \mathrm{s}$ and $2.19 \times 10^{-9} \mathrm{~mm}^{2} / \mathrm{s}$ on the right and left side, respectively. The volume of the lateral ventricles was $7.1 \mathrm{~cm}^{3} . \mathbf{b}, \mathrm{ADC}$ values were $3.14 \times 10^{-9}$ $\mathrm{mm}^{2} / \mathrm{s}$ and $3.02 \times 10^{-9} \mathrm{~mm}^{2} / \mathrm{s}$ on the right and left side, respectively. The volume of the lateral ventricles was $53.3 \mathrm{~cm}^{3}$

$\mathrm{ADC}$, such as mean, standard deviation (SD), minimum, median, and maximum, by subsite and tumor type were calculated. First, univariate analysis was conducted to compare ADC values and ventricular volumes between the LMD and control groups by two-sample t-test. Second, multiple linear regression was used to determine the mean difference of ADCs between the LMD and control groups after adjusting for ventricle size and tumor type. The regression equation is presented as:

$$
\begin{aligned}
y_{A D C}= & b_{0}+b_{1} * x_{\text {ventricle size }}+b_{2} * x_{\text {Tumor type }} \\
& +b_{3} * x_{L M D / \text { control group }}
\end{aligned}
$$

These estimates determine the relationship between the independent variables (the ventricle size, tumor type, and LMD/control group) and the dependent variable (ADC). Third, scatter plots were generated at each site in the ventricular system to compare the adjusted lateral ventricular volume to the ADC values.

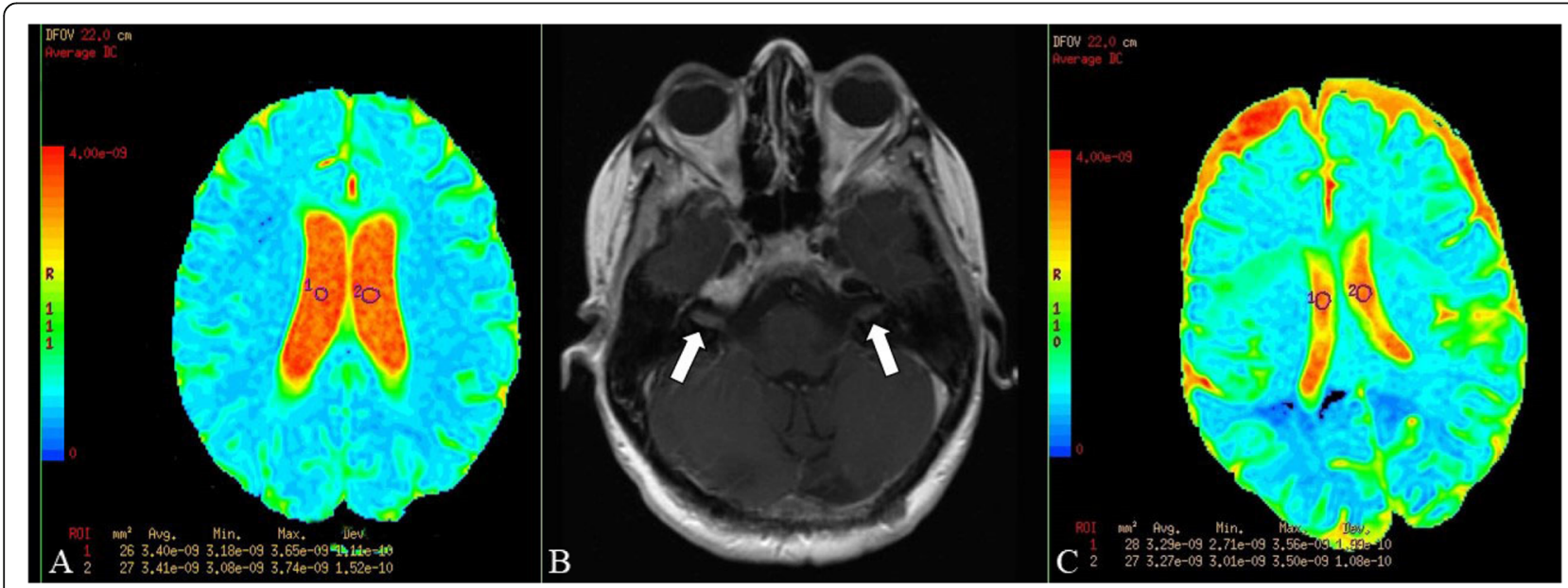

Fig. $2 \mathrm{ROI}$ placement in the mid body of the lateral ventricles in patients with LMD. a, Breast cancer with LMD. ADC values were $3.4 \times 10^{-9} \mathrm{~m}^{2} / \mathrm{s}$ and $3.41 \times 10^{-9} \mathrm{~m}^{2} / \mathrm{s}$ on the right and left side, respectively. The volume of the lateral ventricles was $60.4 \mathrm{~cm}^{3}$. b. Axial T1 post-image series. LMD characterized by diffuse enhancement in the bilateral internal auditory canals (arrows). c, Lymphoma with LMD. ADC values were $3.29 \times 10^{-9} \mathrm{~m}^{2} / \mathrm{s}$ and $3.27 \times 10^{-9} \mathrm{~m}^{2} / \mathrm{s}$ on the right and left side, respectively. The volume of the lateral ventricles was $13.4 \mathrm{~cm}^{3}$. No abnormalities were present on the T1 post-contrast or FLAIR series (not shown) 
Fourth, to determine if ventricular ADC values could predict the presence of LMD, receiver operating characteristics (ROC) analysis was performed to determine the area under the ROC curve and optimal ADC value cut-off point in predicting the presence of LMD with associated sensitivity and specificity. ROC analysis was also performed on the average $\mathrm{HU}$ value from each of the 6 measured site in the lateral ventricles.

Finally, the Fisher exact test was used to compare the presence of $\mathrm{T} 1$ enhancement and sulcal FLAIR signal hyperintensity in the breast cancer and lymphoma LMD and controls groups. Multiple logistic regressions were used to determine if the presence of LMD on conventional MRI, as characterized by T1 enhancement or sulcal FLAIR signal hyperintensity, could be predicted by the ADC values in the ventricles. All tests were twosided and $p$-values of 0.05 or less were considered statistically significant. Statistical analysis was carried out using SAS version 9.4 (SAS Institute, Cary, NC).

\section{Results}

Seventeen consecutive patients with breast cancer and LMD (15 women and 2 men, age range 32-70 years, mean $49.5 \pm 10.6$ years) and 15 consecutive patients with lymphoma and LMD (10 men and 5 women, 29-81, mean $56.4 \pm 16.5$ years) confirmed via cytological evaluation formed the study group. One outlier patient in the lymphoma LMD study group was excluded due to an excessively large ventricular size. The control group comprised 20 consecutive patients with a prior history of breast cancer (19 women and 1 man; 31-68, $52 \pm 7.8$ years,) and 20 consecutive patients with a prior history of lymphoma (11 men and 9 women; age 3-71 $53.2 \pm$ 20.2 years) who were clinically NED.

The ICC between the 2 reviewers for the measurement of ADC values at all sites were $\geq 0.81$ (excellent) (Table 1).

Table 1 ADC measurement inter-observer variability

\begin{tabular}{lll}
\hline ADC location & ICC & ICC $95 \%$ Cl \\
\hline Right frontal horn & 0.97 & $0.96-0.98$ \\
Left frontal horn & 0.81 & $0.71-0.88$ \\
Right lateral ventricle & 0.93 & $0.89-0.95$ \\
Left lateral ventricle & 0.89 & $0.84-0.93$ \\
Right atrium & 0.83 & $0.74-0.89$ \\
Left atrium & 0.97 & $0.96-0.98$ \\
3rd ventricle & 0.98 & $0.96-0.99$ \\
4th ventricle & 0.95 & $0.93-0.97$ \\
\hline \hline 0.40, poor $0.41-0.60, m 0 d$ &
\end{tabular}

$<0.40$, poor; $0.41-0.60$, moderate

$0.61-0.80$, good; $\geq 0.81$, excellent

\section{Comparison of $A D C$ values and ventricular volumes}

The average ADC values of the reviewers comparing the control and LMD group are provided in Table 2. Without adjusting for the ventricular volumes, a significant difference in ADC values was noted between the breast cancer control and breast cancer LMD groups in the following sites: right frontal horn $(p<0.014)$, left frontal horn $(p<0.044)$, right mid-body $(p<0.033)$, right atrium $(p<0.004)$, left atrium $(p<0.043)$, and third ventricle $(p<0.013)$. For the patients with lymphoma a significant difference in ADC values between control and LMD groups was present in the left frontal horn $(\mathrm{p}<0.044)$, left mid-body $(p<0.46)$ and third ventricle $(p<0.018)$. When averaging the ADC values in the lateral ventricles, there was a significant difference between the breast cancer group and control group $(p=0.006)$ while the lymphoma group approached significance $(p=$ 0.052). Ventricular volume measurements are provided in Table 3. For the breast cancer groups there was a significantly larger size of the lateral ventricles $(p=0.005)$ and the total ventricular volume $(p=0.004)$ in the LMD group compared to controls. No significant difference was noted between ventricular sizes in the lymphoma LMD versus control group $(p>0.05)$.

\section{Difference of $A D C$ values after adjusting for ventricle size and tumor type}

After adjusting for ventricular volume and tumor type, a significant difference in ventricular volume between the control and LMD groups was found at all sites except for left $(p>0.058)$ mid-body of the lateral ventricles, although this sits approached a significant difference. When comparing the ADC values between the patients with breast cancer and lymphoma who had LMD, a significant difference was found in the right $(p<0.048)$ and left $(p<0.001)$ atrium and in the third ventricles $(p<$ 0.002 ) with the lymphoma group having higher ADC values. When comparing $\mathrm{ADC}$ values between the control groups and the patients with LMD, a significant difference was noted between the ADC values at all sites except for the left atrium $(p>0.09)$ and fourth ventricle $(p>0.068)$. When averaging the HU values in the lateral ventricles, a significant difference was found in ventricular size between the control and LMD groups $(p<$ 0.001). No significant difference was found between the ADC values of the breast cancer and lymphoma groups $(p=0.18)$ but there was a difference in ADC values between the control and LMD groups $(p=0.001)$. These results are summarized in Table 4.

Review of the scatterplots showed that the ADC values had the least ADC value fluctuation across different ventricular size in the right and left mid-body of the lateral ventricles as illustrated in Fig. 3. 
Table 2 Comparison of ADC values between LMD and control groups at various sites in the ventricular system

\begin{tabular}{|c|c|c|c|c|c|c|}
\hline Site & Disease & & control & LMD & Total & $p$ value \\
\hline \multirow[t]{4}{*}{ Right frontal horn } & Breast & $\mathrm{N}$ & 20 & 17 & 37 & 0.014 \\
\hline & & Mean (SD) & $2.55(0.73)$ & $3.06(0.36)$ & $2.79(0.64)$ & \\
\hline & Lymphoma & $\mathrm{N}$ & 20 & 15 & 35 & 0.051 \\
\hline & & Mean (SD) & $2.76(0.69)$ & $3.14(0.25)$ & $2.92(0.57)$ & \\
\hline \multirow[t]{4}{*}{ Left frontal horn } & Breast & $\mathrm{N}$ & 20 & 17 & 37 & 0.044 \\
\hline & & Mean (SD) & $2.79(0.56)$ & $3.11(0.35)$ & $2.94(0.50)$ & \\
\hline & Lymphoma & $\mathrm{N}$ & 20 & 15 & 35 & 0.071 \\
\hline & & Mean (SD) & $2.95(0.46)$ & $3.17(0.13)$ & $3.04(0.37)$ & \\
\hline \multirow[t]{4}{*}{ Right mid body } & Breast & $\mathrm{N}$ & 20 & 17 & 37 & 0.033 \\
\hline & & Mean (SD) & $3.04(0.38)$ & $3.26(0.13)$ & $3.14(0.31)$ & \\
\hline & Lymphoma & $\mathrm{N}$ & 20 & 15 & 35 & 0.122 \\
\hline & & Mean (SD) & $3.18(0.21)$ & $3.28(0.11)$ & $3.22(0.18)$ & \\
\hline \multirow[t]{4}{*}{ Left mid body } & Breast & N & 20 & 17 & 37 & 0.104 \\
\hline & & Mean (SD) & $3.15(0.29)$ & $3.28(0.11)$ & $3.21(0.23)$ & \\
\hline & Lymphoma & $\mathrm{N}$ & 20 & 15 & 35 & 0.046 \\
\hline & & Mean (SD) & $3.19(0.19)$ & $3.30(0.07)$ & $3.24(0.16)$ & \\
\hline \multirow[t]{4}{*}{ Right atrium } & Breast & $\mathrm{N}$ & 20 & 17 & 37 & 0.004 \\
\hline & & Mean (SD) & $2.70(0.48)$ & $3.10(0.25)$ & $2.89(0.43)$ & \\
\hline & Lymphoma & $\mathrm{N}$ & 20 & 15 & 35 & 0.25 \\
\hline & & Mean (SD) & $3.07(0.36)$ & $3.21(0.32)$ & $3.13(0.34)$ & \\
\hline \multirow[t]{4}{*}{ Left atrium } & Breast & $\mathrm{N}$ & 20 & 17 & 37 & 0.043 \\
\hline & & Mean (SD) & $2.81(0.45)$ & $3.09(0.34)$ & $2.94(0.42)$ & \\
\hline & Lymphoma & $\mathrm{N}$ & 20 & 15 & 35 & 0.628 \\
\hline & & Mean (SD) & $3.24(0.26)$ & $3.28(0.23)$ & $3.26(0.24)$ & \\
\hline \multirow[t]{4}{*}{ 3rd ventricle } & Breast & Number & 20 & 17 & 37 & 0.013 \\
\hline & & Mean (SD) & $2.72(0.54)$ & $3.15(0.45)$ & $2.92(0.54)$ & \\
\hline & Lymphoma & $\mathrm{N}$ & 20 & 15 & 35 & 0.018 \\
\hline & & Mean (SD) & $3.16(0.36)$ & $3.42(0.19)$ & $3.27(0.33)$ & \\
\hline \multirow[t]{4}{*}{ 4th ventricle } & Breast & $\mathrm{N}$ & 20 & 17 & 37 & 0.452 \\
\hline & & Mean (SD) & $3.39(0.23)$ & $3.46(0.34)$ & $3.42(0.29)$ & \\
\hline & Lymphoma & N & 20 & 15 & 35 & 0.079 \\
\hline & & Mean (SD) & $3.38(0.31)$ & $3.54(0.17)$ & $3.45(0.27)$ & \\
\hline \multirow[t]{4}{*}{ Lateral ventricle (average) } & Breast & $\mathrm{N}$ & 20 & 17 & 37 & 0.006 \\
\hline & & Mean (SD) & $2.84(0.39)$ & $3.15(0.21)$ & $2.98(0.35)$ & \\
\hline & Lymphoma & $\mathrm{N}$ & 20 & 15 & 35 & 0.052 \\
\hline & & Mean (SD) & $3.07(0.29)$ & $3.23(0.14)$ & $3.14(0.25)$ & \\
\hline
\end{tabular}

$N$ Number

$S D$ standard deviation

\section{ROC analysis}

The mid-body of the left lateral ventricles was the only site without a significant difference in ventricular volume that also showed a significant difference in ADC values when patients with LMD were compared to the control groups. As the mid-body of the lateral ventricles also showed the least fluctuation on the scatterplots, ROC analysis was performed on the ADC values measured in this location. In the mid-body of the right lateral ventricle the AUC was 0.69 (95\% CI 0.57-0.81) with an optimal cut off point of $3.22 \times 10^{-9} \mathrm{~m}^{2} / \mathrm{s}$ (sensitivity, specificity; 0.72, 0.68). In the mid-body of left lateral ventricle the AUC was 0.7 (95\% CI 0.58-0.82) with an optimal cut off point of $3.23 \times 10^{-9} \mathrm{~m}^{2} / \mathrm{s}(0.81,0.62)$. 
Table 3 Comparison of ventricular volumes between control and LMD groups

\begin{tabular}{|c|c|c|c|c|c|c|}
\hline Site & Disease & & control & LMD & Total & $p$ value \\
\hline \multirow[t]{4}{*}{ Lateral ventricles } & Breast & $\mathrm{N}$ & 20 & 17 & 37 & 0.005 \\
\hline & & Mean (SD) & $18.06(8.40)$ & $30.29(15.64)$ & $23.68(13.57)$ & \\
\hline & Lymphoma & N & 20 & 15 & 35 & 0.454 \\
\hline & & Mean (SD) & $1.85(1.05)$ & $2.10(0.80)$ & $1.96(0.95)$ & \\
\hline \multirow[t]{4}{*}{ 3rd ventricle } & Breast & $\mathrm{N}$ & 20 & 17 & 37 & 0.052 \\
\hline & & Mean (SD) & $0.91(0.37)$ & $1.98(2.35)$ & $1.40(1.68)$ & \\
\hline & Lymphoma & $\mathrm{N}$ & 20 & 15 & 35 & 0.454 \\
\hline & & Mean (SD) & $1.85(1.05)$ & $2.10(0.80)$ & $1.96(0.95)$ & \\
\hline \multirow[t]{4}{*}{ 4th ventricle } & Breast & $\mathrm{N}$ & 20 & 17 & 37 & 0.663 \\
\hline & & Mean (SD) & $1.01(0.30)$ & $1.09(0.75)$ & $1.05(0.55)$ & \\
\hline & Lymphoma & $\mathrm{N}$ & 20 & 15 & 35 & 0.925 \\
\hline & & Mean (SD) & $1.14(0.50)$ & $1.13(0.40)$ & $1.14(0.45)$ & \\
\hline \multirow[t]{4}{*}{ Total volume } & Breast & $\mathrm{N}$ & 20 & 17 & 37 & 0.004 \\
\hline & & Mean (SD) & 19.98 (8.73) & $33.37(17.22)$ & $26.13(14.76)$ & \\
\hline & Lymphoma & $\mathrm{N}$ & 20 & 15 & 35 & 0.568 \\
\hline & & Mean (SD) & $36.90(19.59)$ & $33.40(14.90)$ & $35.40(17.58)$ & \\
\hline
\end{tabular}

$N$ Number

$S D$ standard deviation

Using an average value of HU measurements in the lateral ventricles the AUC was 0.73 (95\% CI 0.61-0.84) optimal cut off point was $3.11 \times 10^{-9} \mathrm{~m}^{2} / \mathrm{s}(0.78,0.65)$ (Fig. 4).

\section{Correlation of T1 post contrast and FLAIR findings with ADC values}

A significant difference in the occurrence rate of T1 enhancement $(p<0.001)$ was noted in the patients with LMD and breast cancer $(n=16 / 17,91.4 \%)$ compared to patients with LMD and lymphoma $(n=6 / 15,40 \%)$. Sulcal FLAIR signal hyperintensity in the breast cancer group $(n=14 / 17,82.4 \%)$ and the lymphoma group ( $n=$ $8 / 15,53.3 \%)$ were not associated with a significant difference in the rate of occurrence $(p>0.08)$. Multiple logistic regressions to predict the presence of LMD by ADC values after adjusting for the presence of $\mathrm{T} 1$ enhancement showed that ADC was predictive of the presence of LMD in the left mid body of the left lateral ventricle $(p=0.036)$. No significant difference in ADC values at the remaining sites in the ventricular system was noted $(p>0.05)$. Multiple logistic regressions to predict the presence of LMD by ADC values after adjusting for the presence of FLAIR signal hyperintensity showed that ADC was not predictive of the presence of LMD at any of the measured sites $(p>0.05)$.

\section{Discussion}

Our results demonstrated that ADC values in the ventricles in patients with LMD are greater than in a control group without LMD. This finding is the opposite of our hypothesis that the ADC values in the ventricles in patients with LMD would be lower than controls owing to compartmentalization of CSF and suggests relatively freer movement in the LMD group. ROC analysis showed that ADC values measured in the mid-body of the lateral ventricles performed best to predict the presence of LMD. The AUC could be slightly improved by finding an average $\mathrm{ADC}$ value by measuring multiple sites in the lateral ventricles. When compared to the T1 post-contrast series the ADC values in the left mid-body of the left lateral ventricle correlated with the presence of LMD.

Complex interactions govern the movement of CSF through the ventricular system. This movement may be similar to Poiseuille's law for the flow of fluid through a tube, represented by in the following equation:

$$
Q=\frac{\Delta P \pi r^{4}}{8 \eta l}
$$

Where $Q$ is the flow rate, $\Delta P$ is the pressure differential between the two ends, $r$ is the radius, $\eta=$ is the viscosity of the fluid and $l$ is the tube length. The flow rate is directly proportional to the 4 th power of the radius of the tube. Thus, an increase in ventricular size, intracranial pressure and CSF viscosity may affect the flow rate.

Other factors affect the movement of CSF through the ventricular system. During systole, CSF flow is cranial to caudal while in diastole the flow reverses from caudal to 
Table 4 Difference of ADC values after adjusting for ventricle size and tumor type

\begin{tabular}{|c|c|c|c|c|}
\hline Site & Covariate & Beta & $95 \% \mathrm{Cl}$ & $p$ value \\
\hline \multirow[t]{3}{*}{ Right frontal horn } & Volume & 0.021 & $0.013,0.028$ & $<0.001$ \\
\hline & Tumor & -0.03 & $-0.268,0.201$ & 0.775 \\
\hline & Group LMD & 0.352 & $0.123,0.581$ & 0.003 \\
\hline \multirow[t]{3}{*}{ Left frontal horn } & Volume & 0.01 & $0.004,0.016$ & 0.002 \\
\hline & Tumor & 0.027 & $-0.166,0.22$ & 0.779 \\
\hline & Group LMD & 0.233 & $0.045,0.422$ & 0.016 \\
\hline \multirow[t]{3}{*}{ Right mid body } & Volume & 0.004 & $0,0.008$ & 0.036 \\
\hline & Tumor & 0.051 & $-0.065,0.167$ & 0.382 \\
\hline & Group LMD & 0.138 & $0.025,0.252$ & 0.018 \\
\hline \multirow[t]{3}{*}{ Left mid body } & Volume & 0.003 & $0,0.006$ & 0.058 \\
\hline & Tumor & 0.012 & $-0.081,0.104$ & 0.805 \\
\hline & Group LMD & 0.103 & $0.013,0.194$ & 0.026 \\
\hline \multirow[t]{3}{*}{ Right atrium } & Volume & 0.009 & $0.004,0.015$ & 0.001 \\
\hline & Tumor & 0.171 & $0.002,0.341$ & 0.048 \\
\hline & Group LMD & 0.103 & $0.013,0.194$ & 0.026 \\
\hline \multirow[t]{3}{*}{ Left atrium } & Volume & 0.007 & $0.001,0.012$ & 0.013 \\
\hline & Tumor & 0.271 & $0.11,0.432$ & 0.001 \\
\hline & Group LMD & 0.135 & $-0.022,0.292$ & 0.09 \\
\hline \multirow[t]{3}{*}{ 3rd ventricle } & Volume & 0.121 & $0.052,0.191$ & $<0.001$ \\
\hline & Tumor & 0.297 & $0.111,0.483$ & 0.002 \\
\hline & Group LMD & 0.268 & $0.079,0.457$ & 0.006 \\
\hline \multirow[t]{3}{*}{ 4th ventricle } & Volume & 0.264 & $0.15,0.378$ & $<0.001$ \\
\hline & Tumor & 0.012 & $-0.102,0.126$ & 0.832 \\
\hline & Group LMD & 0.106 & $-0.008,0.22$ & 0.068 \\
\hline \multirow[t]{3}{*}{ Lateral average } & Volume & 0.009 & $0.005,0.013$ & $<0.001$ \\
\hline & Tumor & 0.083 & $-0.039,0.205$ & 0.18 \\
\hline & Group LMD & 0.198 & $0.079,0.318$ & 0.001 \\
\hline
\end{tabular}

cranial, filling the lateral ventricles. Overall, there is net caudal flow of CSF related to its production. However, the reversal of flow in diastole induces a complex mixing pattern in the ventricles. The flow of CSF into the spinal canal is related to the gradient between the intracranial compartment [28] and the more compliant nature of the spinal canal. The degree of compliance is believed to be related to the venous plexus, ligamentum flavum and the nerve sheaths [29-31].

Linninger et al. [32] studied CSF flow in the normal brain compared to hydrocephalic brain. They found that in a hydrocephalic brain the peak CSF flow velocity increased by 2.7 times compared to the normal brain. In addition, the larger ventricular dimensions and increased CSF pulsatility increased the rate of volumetric flow by a factor of 10. They also observed that complex CSF flow patterns resulted in stagnant areas and eddy formation in the hydrocephalic brain.
Helenius et al. [33] measured the ADC values in the frontal horn and mid-body of the lateral ventricles in 80 patients including 20 of each in the following age groups: $20-34$ years, $35-49$ years, and $50-64$ years and greater than 65 years old. They found that as patients aged, the ADC values increased and attributed the progressive ADC increase to ventricular enlargement with corresponding increase in turbulent CSF flow. In Helenius' study the average ADC measurement in entire group of 80 patients in the right and left frontal horns was $2.74 \pm 0.27 \times 10^{-3} \mathrm{~mm} / \mathrm{s}^{2}$ and $2.73 \pm 0.27 \times 10^{-3}$ $\mathrm{mm} / \mathrm{s}^{2}$, respectively. For patient aged $50-64$, which is closest to the mean age of the control groups in our study [breast cancer ( $52 \pm 7.8$ years); lymphoma ( $53.2 \pm$ 20.2 years)], the average ADC values were $2.79 \pm 0.5 \times$ $10^{-3} \mathrm{~mm} / \mathrm{s}^{2}$ and $2.78 \pm 0.25 \times 10^{-3} \mathrm{~mm} / \mathrm{s}^{2}$. The values of the breast cancer control group in our study were slightly lower in the right frontal horn $2.55 \pm 0.73 \times 10^{-3}$ $\mathrm{mm} / \mathrm{s}^{2}$ (breast) but comparable on the left $2.79 \pm 0.56 \times$ $10^{-3} \mathrm{~mm} / \mathrm{s}^{2}$. In the lymphoma control group (mean age $53.2 \pm 20.2$ years) the average ADC value in the left frontal horn was comparable $2.76 \pm 0.69 \times 10^{-3} \mathrm{~mm} / \mathrm{s}^{2}$ but slightly higher in the left frontal horn $2.93 \pm 0.46 \times$ $10^{-3} \mathrm{~mm} / \mathrm{s}^{2}$.

In the right and left mid body of the lateral ventricle the average ADC measurements in entire group of 80 patients in Helenius' study $3.02 \pm 0.16 \times 10^{-3} \mathrm{~mm} / \mathrm{s}^{2}$ on both sides for the entire group and in the 50-64 age group were $3.03 \pm 0.15 \times 10^{-3} \mathrm{~mm} / \mathrm{s}^{2}$ and $3.05 \pm 0.15 \times$ $10^{-3} \mathrm{~mm} / \mathrm{s}^{2}$ on the right and left, respectively. The ADC values of the breast cancer control group in our study were comparable in the right mid body $3.04 \pm 0.3810^{-3}$ $\mathrm{mm} / \mathrm{s}^{2}$. The ADC values were also slightly higher in the mid body of the right lateral ventricle in the lymphoma control group $\left(3.18 \pm 0.2210^{-3} \mathrm{~mm} / \mathrm{s}^{2}\right)$, and also slightly higher in left lateral ventricle in both the breast cancer control groups $\left(3.15 \pm 0.2910^{-3} \mathrm{~mm} / \mathrm{s}^{2}\right)$ and the lymphoma control group $\left(3.19 \pm 0.1910^{-3} \mathrm{~mm} / \mathrm{s}^{2}\right)$. Differences in Helenius' study and ours may be related to the small sample size in both groups as well as the post-treatment state with potentially larger size of the ventricles of the control group in our study due to treatment associated volume loss versus normal volunteers in Helenius' group. Another factor may also be the different position of the ROI in the body of the lateral ventricle in Helenius' study which was more anterior and closer to the foramen of Monro.

In patients with LMD, other factors may complicate the movement of CSF. Infiltration of tumor into the arachnoid villi, Sylvian fissures base of the brain may impede CSF outflow leading to hydrocephalus and increasing the intracranial pressure [34]. Potentially further complicating the movement of CSF is the adherence of tumor cells to the ventricular walls. For fluid flowing 


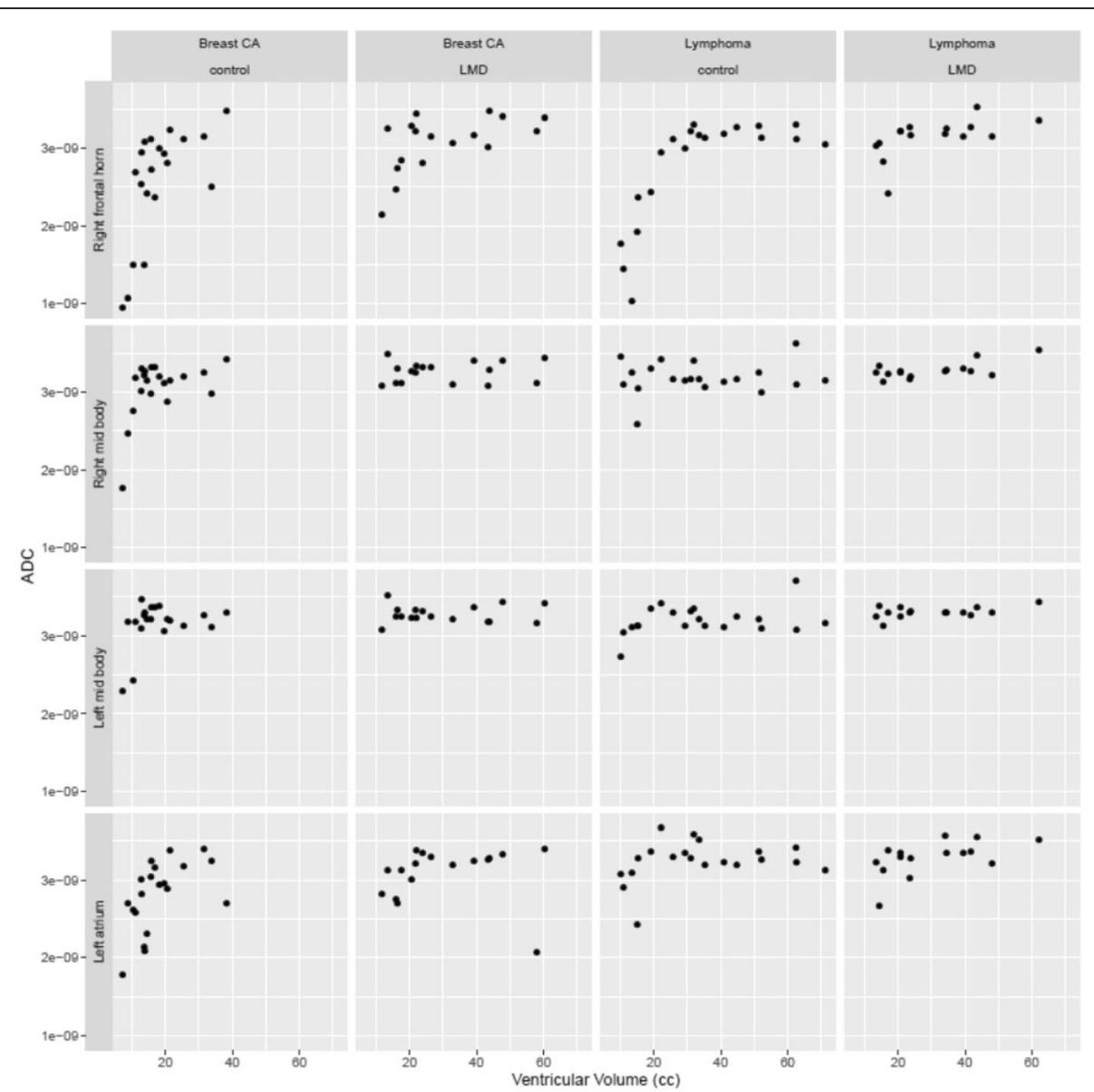

Fig. 3 Scattergram of ventricular volume versus ADC values in selected locations. The least fluctuation ADC value across different ventricular volumes was in the right and left mid body of the lateral ventricles

past a rough wall there may be alteration of the heat transference rate via increased turbulence [35]. There may be additional perturbations in flow dynamics of CSF with metastatic deposits within or involving the spinal canal - a consideration we did not evaluate in this study.

In our study, we first compared the ADC values in the control versus study groups at each of the measured sites without adjusting for ventricular size and tumor type. We found that there was a significant difference in $\mathrm{ADC}$ values at more sites in the breast cancer group than the lymphoma group. When averaging the ADC values in the lateral ventricles, there was a significant difference between the breast cancer group and control group $(p=0.006)$ while the lymphoma group approached significance $(p=0.052)$. We then compared the ventricular volume measurements in the control versus study groups again without adjusting for ventricular size and tumor type. Our results showed a significant significantly lower volume of the lateral ventricles and total ventricular volume in the breast cancer control group. No significant difference was noted in the volumes in the lymphoma control versus LMD group. This combination of more sites with differences in ADC values between the breast cancer control and LMD group and the significant differences in the ventricular size confirms that a change in ventricular volume may affect the diffusivity of CSF and thus the ADC values.

After adjusting for ventricular volume and tumor type, we found a significant difference in ventricular volume between the control and LMD groups at all sites except for the mid-body of the left lateral ventricles although this site approached a significant difference. Analysis of the scatterplots that compared the adjusted ventricular volume to ADC also showed the least fluctuation in the mid-body of the lateral ventricles. Possible explanations for these findings could include the small sample size and possibly that the lateral ventricular and left atrial volumes were already increased in size in the post-treatment control population or that these sites are less susceptible to change with the presence of active LMD. 


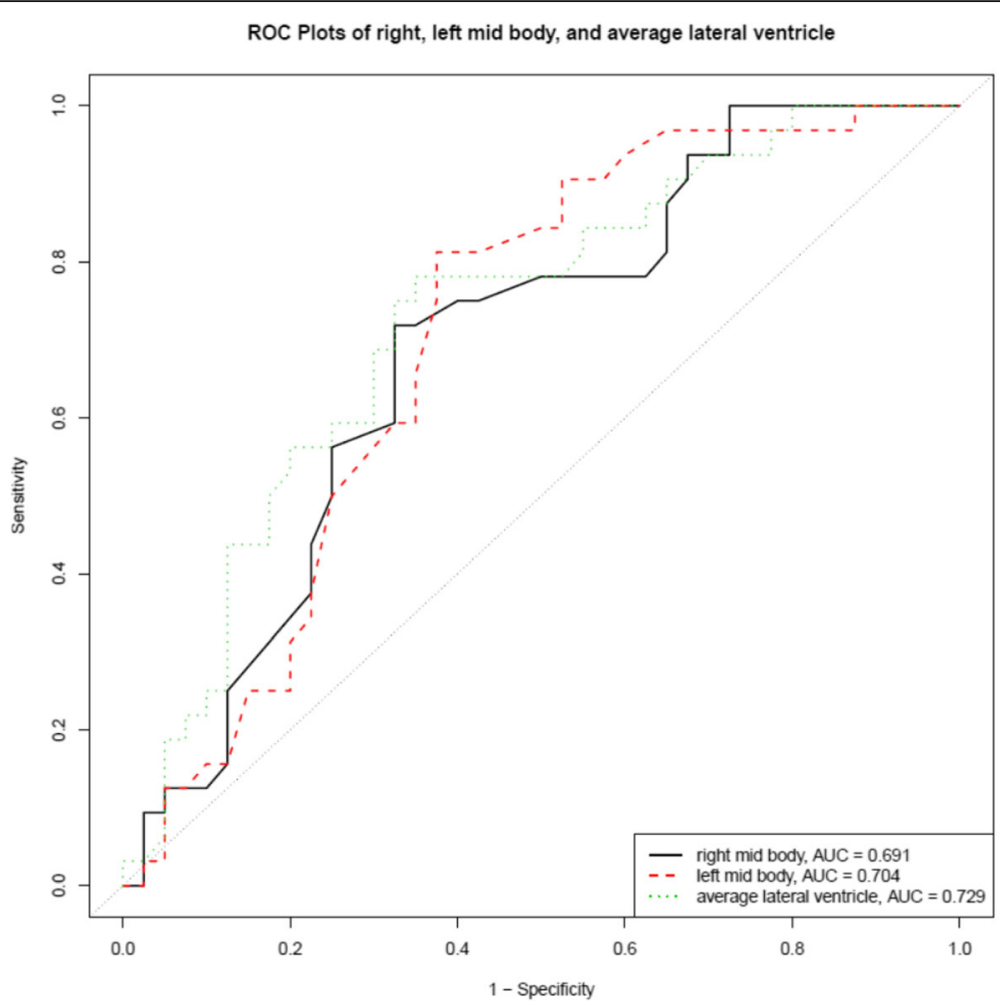

Fig. 4 ROC curve from ADC values obtained from the mid body of the lateral ventricles. In the mid body of the right lateral ventricle the AUC was $0.69\left(95 \% \mathrm{Cl} 0.57-0.81\right.$ ) with an optimal cut off point of $3.22 \times 10^{-9} \mathrm{~m}^{2} / \mathrm{s}$. In the mid body of left lateral ventricle the AUC was 0.7 (95\% Cl $0.58-0.82$ ) with an optimal cut off point of $3.23 \times 10^{-9} \mathrm{~m}^{2} / \mathrm{s}$. Using an average value of HU measurements in the lateral ventricles the AUC was $0.73(95 \% \mathrm{Cl} 0.61-0.84)$ with an optimal cut off point of $3.11 \times 10^{-9} \mathrm{~m}^{2} / \mathrm{s}(0.78,0.65)$

When comparing the ADC values between the patients with breast cancer and lymphoma who had LMD, a significant difference was found in the right $(p<0.048)$ and left $(p<0.001)$ atrium and in the third ventricles $(p<0.002)$ with the lymphoma group having a higher $\mathrm{ADC}$ values. When comparing ADC values between the control groups and the patients with LMD, a significant difference was noted between the ADC values at all sites except for the left atrium $(p>0.09)$ and fourth ventricle $(p>0.068)$ although these approached a significant difference. We postulate that these findings could be also secondary to sample size or possibly complex interactions of the flow dynamics in the atria, third and fourth ventricles including factors such as an increase flow rate through the foramen of Monro and inherent changes in CSF flow in the ventricles.

In [33] our study, multiple logistic regressions showed that of ADC values in the mid body of the left lateral ventricle were predictive of the presence of LMD. Other sites were not predictive of the presence of LMD, including the right lateral ventricle. This may be related to the significantly higher ADC values noted in the left lateral ventricle in the lymphoma LMD group before correcting for ventricular size and the variation in ventricular size between the breast cancer control and LMD groups. Other contributing factors may also be that the control patients in our study were previously treated for cancer, including radiation therapy that could have altered the ventricular system due to cerebral volume loss or local toxicity. This is demonstrated by the higher ADC values in our control groups compared to the study in normal volunteers by Helenius et al. The relative small sample size may have been another contributing factor.

When measuring the average $\mathrm{HU}$ values in the lateral ventricles between the control and LMD groups a significant difference was noted between the ventricular volume and between ADC values. Therefore, further study is necessary to determine the effect of ventricular size on ADC values as governed by Poiseuille's law. The significantly more common occurrence of $\mathrm{T} 1$ enhancement in the breast cancer LMD group than the lymphoma LMD group may have impacted our results. Other limitations include the retrospective single-institutional study and partial volume effects inherent in any ROI measurements. In addition, we used CSF cytology as the gold standard for the presence of LMD. As CSF cytology is only $80-95 \%$ sensitive [4] there may be an 
underestimation of the sensitivity of our results. These factors as well as comparing ventricular ADC values to contrast enhanced FLAIR sequences that are superior to T1 post-contrast sequence for detection of leptomeningeal enhancement [35] could be the subject of future investigations. Further studies could also use artificial intelligence for segmentation of the lateral ventricles or the entire ventricular system to determine if a single $A D C$ value aids in detecting the presence of LMD.

\section{Conclusion}

Complex interactions including ventricular size, flow rate, pressure, CSF viscosity and eddy formation may alter the movement of CSF and affect ADC measurements within the ventricular system in patients with LMD. Elevated ADC values in the lateral ventricles may provide non-invasive clues for the diagnosis of LMD. This study may serve as a baseline to guide future investigations on the use of ventricular ADC values in patients with neoplastic LMD for both validation and refinement before clinical implementation.

\section{Abbreviations}

LMD: Leptomeningeal disease; ICC: Intraclass correlation coefficient; SD: Standard deviation; ROC: Receiver operating characteristic; NED: No evidence of disease

\section{Acknowledgements}

Not applicable.

\section{Authors' contributions}

JMD was involved with conception of the project, acquisition of data, analysis of data, interpretation of data, drafting the work and was a major contributor in writing the manuscript. RBS was involved with acquisition of data, analysis of data and drafting the work. HHL was involved with conception of the project, acquisition of data, analysis of data, interpretation of data, drafting the work, and was a major contributor in writing the manuscript. JS was involved with was involved with analysis of data, interpretation of data and drafting the work. JW was involved with conception of the project, acquisition of data, analysis of data, interpretation of data, creation of new software used in the work, and drafting the work. WW was involved with analysis of data and interpretation of data. DS was involved with analysis of data, interpretation of data and drafting the work. RRM acquisition of data and drafting the work. TLC was involved in acquisition of data, analysis of data, and drafting the work. LK was involved in acquisition of data, analysis of data, and drafting the work. NGT was involved with conception of the project, acquisition of data, analysis of data and drafting the work. JSW was involved with conception of the project and was a major contributor in writing the manuscript. The authors read and approved the final manuscript.

\section{Funding}

No direct funding for the manuscript. The University of Texas MD Anderson Cancer Center is supported in part by the National Institutes of Health through Cancer Center Support Grant CA016672.

\section{Availability of data and materials}

Not applicable.

\section{Ethics approval and consent to participate}

Provided in the Methods section on page 3, as follows: The study was approved by our Institutional Review Board who waived the requirement for informed consent. Data acquisition was performed in compliance with all applicable Health Insurance Portability and Accountability Act regulations.
Consent for publication

Not applicable.

\section{Competing interests}

The authors declare that they have no competing interests.

\section{Author details}

${ }^{1}$ Department of Neuroradiology, The University of Texas MD Anderson Cancer Center, 1400 Pressler Blvd., Unit 1482, Houston, TX 77030, USA. ${ }^{2}$ Department of Biostatistics, The University of Texas MD Anderson Cancer Center, Houston, TX, USA. ${ }^{3}$ Department of Radiation Physics, The University of Texas MD Anderson Cancer Center, Houston, TX, USA. ${ }^{4}$ Department of Neurosurgery, The University of Texas MD Anderson Cancer Center, Houston, TX, USA. ${ }^{5}$ Department of Neurosurgery, University of California San Francisco, San Francisco, CA, USA.

Received: 2 December 2019 Accepted: 1 April 2020

Published online: 29 June 2020

\section{References}

1. Chamberlain MC. Current concepts in leptomeningeal metastasis. Curr Opin Oncol. 1992;4(3):533-9.

2. Grossman SA, Moynihan TJ. Neoplastic meningitis. Neurol Clin. 1991;9(4): 843-56.

3. DeAngelis LM. Current diagnosis and treatment of leptomeningeal metastasis. J Neuro-Oncol. 1998;38(2-3):245-52.

4. Bruna J, Simó M, Velasco R. Leptomeningeal metastases. Curr Treat Options Neurol. 2012;14(4):402-15.

5. Drappatz J, Batchelor TT. Leptomeningeal neoplasms. Curr Treat Options Neurol. 2007;9(4):283-93.

6. Chamberlain MC. Leptomeningeal metastasis. Semin Neurol. 2010;30(3):236-44

7. DeAngelis LM, Boutros D. Leptomeningeal metastasis. Cancer Investig. 2005; 23(2):145-54.

8. Brem SS, Bierman PJ, Brem H, Butowski N, Chamberlain MC, Chiocca EA, DeAngelis LM, Fenstermaker RA, Friedman A, Gilbert MR, Hesser D, Junck L, Linette GP, Loeffler JS, Maor MH, Michael M, Moots PL, Morrison T, Mrugala M, Nabors LB, Newton HB, Portnow J, Raizer JJ, Recht L, Shrieve DC, Sills AK $J$ r, Vrionis FD, Wen PY. National comprehensive cancer network, central nervous system. J Natl Compr Cancer Netw. 2011;9(4):352-400.

9. Kremer S, Abu Eid M, Bierry G, Bogorin A, Koob M, Dietemann JL, Fruehlich S. Accuracy of delayed post-contrast FLAIR MR imaging for the diagnosis of leptomeningeal infectious or tumoral diseases. J Neuroradiol. 2006;33(5): 285-91.

10. Wasserstrom WR, Glass JP, Posner JB. Diagnosis and treatment of leptomeningeal metastases from solid tumors: experience with 90 patients. Cancer. 1982;494(4):759-72.

11. Glantz MJ, Cole BF, Glantz LK, Cobb J, Mills P, Lekos A, Walters BC, Recht LD. Cerebrospinal fluid cytology in patients with cancer: minimizing falsenegative results. Cancer. 1998;82(4):733-9.

12. Lossos A, Siegal T. Spinal subarachnoid hemorrhage associated with leptomeningeal metastases. J Neuro-Oncol. 1992:12(2):167-71.

13. Rudnicka H, Niwińska A, Murawska M. Breast cancer leptomeningeal metastasis: The role of multimodality treatment. J Neuro-Oncol. 2007;84(1): 57-62.

14. Clarke JL, Perez HR, Jacks LM, Clarke JL, Perez HR, Jacks LM. Leptomeningeal metastases in the MRI era. Neurology. 2010;74(18):1449-54.

15. Park JH, Kim YJ, Lee JO, Park JH, Kim YJ, Lee JO. Clinical outcomes of leptomeningeal metastasis in patients with non-small cell lung cancer in the modern chemotherapy era. Lung Cancer. 2012;76(3):387-92.

16. Morris PG, Reiner AS, Szenberg OR. Leptomeningeal metastasis from nonsmall cell lung cancer: Survival and the impact of whole brain radiotherapy. J Thorac Oncol. 2012;7(2):382-5.

17. Guenette JP, Tirumani SH, Keraliya AR, Shinagare AB, Ramaiya NH, Jagannathan JP. MRI findings in patients with leukemia and positive CSF cytology: a single-institution 5-year experience. AJR Am J Roentgenol. 2016; 207(6):1278-82.

18. Fitsiori A, Fornecker LM, Simon L, Karentzos A, Galanaud D, Outteryck O, Vermersch P, Pruvo JP, Gerardin E, Lebrun-Frenay C, Lafitte F, Cottier JP, Clerc C, de Seze J, Dietemann JL, Kremer S. Imaging spectrum of Bing-Neel syndrome: how can a radiologist recognise this rare neurological 
complication of Waldenström's macroglobulinemia? Eur Radiol. 2019;29(1): 102-14.

19. Warach S, Chien D, Li W, Edelman RR. Fast magnetic resonance diffusionweighted imaging of acute human stroke. Neurology. 1992;42(9):1717-23.

20. Guo AC, Cummings TJ, Dash RC, Provenzale JM. Lymphomas and highgrade astrocytomas: comparison of water diffusibility and histologic characteristics. Radiology. 2002;224(1):177-83.

21. Yamasaki F, Kurisu K, Satoh K, Arita K, Sugiyama K, Ohtaki M, Takaba J, Tominaga A, Hanaya R, Yoshioka H, Hama S, Ito Y, Kajiwara Y, Yahara K, Saito T, Thohar MA. Apparent diffusion coefficient of human brain tumors at MR imaging. Radiology. 2005;235(3):985-91.

22. Chamberlain MC, Corey-Bloom J. Leptomeningeal metastases: 111 indiumDTPA CSF flow studies. Neurology. 1991;41(11):1765-9.

23. Chamberlain MC. Pediatric leptomeningeal metastasis: $111 \mathrm{ln}$-DTPA cerebrospinal fluid flow studies. J Child Neurol. 1994;9(2):150-4.

24. Haaxma-Reiche H, Piers A, Beekhuis H. Normal cerebrospinal fluid dynamics. A study with intraventricular injection of 111/n-DTPA in leukemia and lymphoma without meningeal involvement. Arch Neurol. 1989;46(9):997-9.

25. Grossman SA, Trump DL, Chen DC, Thompson G, Camargo EE. Cerebrospinal fluid flow abnormalities in patients with neoplastic meningitis. An evaluation using 111 indium-DTPA ventriculography. Am J Med. 1982;73(5):641-7.

26. Chamberlain MC. Radioisotope CSF flow studies in leptomeningeal metastases. J Neuro-Oncol. 1998;38(2-3):135-40.

27. Zhang L, Fried DV, Fave XJ, Hunter LA, Yang J, Court LE. IBEX: an open infrastructure software platform to facilitate collaborative work in radiomics. Med Phys. 2015 Mar;42(3):1341-53.

28. Sweetman B, Linninger AA. Cerebrospinal fluid flow dynamics in the central nervous system. Ann Biomed Eng. 2011;39(1):484-96.

29. Bateman GA. Vascular compliance in normal pressure hydrocephalus. AJNR Am J Neuroradiol. 2000;21(9):1574-85.

30. Czosnyka M, Czosnyka Z, Momjian S, Pickard JD. Cerebrospinal fluid dynamics. Physiol Meas. 2004;25(5):51-76.

31. Henry-Feugeas MC, Idy-Peretti I, Baledent O, Poncelet-Didon A, Zannoli G, Bittoun J, Schouman-Claeys E. Origin of subarachnoid cerebrospinal fluid pulsations: a phase-contrast MR analysis. Magn Reson Imaging. 2000;18(4): 387-95

32. Linninger AA, Xenos M, Zhu DC, Somayaji MR, Kondapalli S, Penn RD. Cerebrospinal fluid flow in the normal and hydrocephalic human brain. IEEE Trans Biomed Eng. 2007;54(2):291-302.

33. Helenius J, Soinne L, Perkiö J, Salonen O, Kangasmäki A, Kaste M, Carano RA, Aronen HJ, Tatlisumak T. Diffusion weighted MR imaging in normal human brains in various age groups. AJNR Am J Neuroradiol. 2002;23(2):194-9.

34. Le Rhun E, Taillibert S, Chamberlain MC. Carcinomatous meningitis: leptomeningeal metastases in solid tumors. Surg Neurol Int. 2013;4(Suppl 4): S265-88.

35. Hosni MH, Coleman HW, Taylor RP. Measurements and calculations of rough-wall heat transfer in the turbulent boundary layer. Int I Heat Mass Transf. 1991;34(4/5):1067-82.

\section{Publisher's Note}

Springer Nature remains neutral with regard to jurisdictional claims in published maps and institutional affiliations.

Ready to submit your research? Choose BMC and benefit from:

- fast, convenient online submission

- thorough peer review by experienced researchers in your field

- rapid publication on acceptance

- support for research data, including large and complex data types

- gold Open Access which fosters wider collaboration and increased citations

- maximum visibility for your research: over $100 \mathrm{M}$ website views per year

At BMC, research is always in progress.

Learn more biomedcentral.com/submissions 